\title{
DIAGNÓSTICO DA EDUCAÇÃO AMBIENTAL NAS ESCOLAS PÚBLICAS DE EDUCAÇÃO BÁSICA NO MUNICÍPIO DE PARAUAPEBAS (PA)
}

Tiago Cordeiro ${ }^{1}$

Resumo: A presente pesquisa teve como objetivo a realização de um diagnóstico da Educação Ambiental no município de Parauapebas-PA. Baseado na metodologia proposta pela CGEA em parceria com IETS, foi encaminhado a todas as escolas públicas municipais um questionário sobre a situação atual da EA. Constatou-se que, nessas unidades, a EA foi recentemente inserida ou ainda não é abordada. Em geral é de iniciativa de professores, através de projetos, e que não inclui totalmente a comunidade escolar. Conclui-se que é necessário intervenções de políticas públicas abrangentes para sua real efetivação bem como a articulação de metodologias para uma melhor compreensão dos objetivos da EA por parte dos atores envolvidos.

Palavras-Chave: Educação Ambiental; Diagnóstico; Escolas Públicas, Educação Básica.

Abstract: This research aimed to make a diagnosis of environmental education in the municipality of Parauapebas-PA. Based on the methodology proposed by CGEA in partnership with IETS, a questionnaire on the current situation of EA was sent to all municipal public schools. It was found that, in these units, EA was recently inserted or is not yet addressed. In general, it is the initiative of teachers, through projects, and it does not fully include the school community. It is concluded that comprehensive public policy interventions are necessary for their real effectiveness, as well as the articulation of methodologies for a better understanding of the objectives of EA by the actors involved.

Keywords: Environmental Education; Diagnosis; Public Schools; Basic Education.

\footnotetext{
1 Universidade Federal do Pará - UFPA. E-mail: tiago.cordeiro.bio@gmail.com. Link para Lattes: http://lattes.cnpq.br/4866564977389569
} 


\section{Introdução}

A Educação Ambiental (EA), está diretamente ligada as concepções ambientais, políticas, econômicas, culturais e sociais. Podendo ser definida como uma prática educativa que objetiva a construção de disposições e ações que possibilitem um entendimento crítico, real e responsável, seja individualmente ou coletivamente, para com o meio. Sendo assim, torna-se indissociável sua relação com a percepção e prática comum de educação realizada nas escolas. Neste sentido, os Parâmetros Curriculares Nacionais (PCN's) definem que temas como: ética, meio ambiente, pluralidade cultural, saúde, trabalho e consumo e orientação sexual, são de relevância transversal que necessitam serem abordados entre as disciplinas (BRASIL, 1997, p. 41). Contudo, na prática, a inserção da EA nas escolas ainda acontece de forma precária, seja em relação ao quantitativo de escolas que conseguiram efetivamente inseri-la no seu cotidiano, ou ainda em relação a metodologia que está sendo aplicada. Diante disso, é de interesse deste trabalho, a compreensão acerca do cenário atual da EA no contexto da educação básica nas escolas públicas, sob o olhar direto dos atores envolvidos na educação. Busca-se a construção de análises e reflexões sobre como a EA vem sendo aplicada, abarcando ainda sua práxis metodológica e seus possíveis entraves, possibilitando assim uma contribuição teórica significativa acerca do tema, podendo ainda fornecer subsídios à comunidade escolar para o fomento e construção de políticas públicas voltadas para este tema.

Portanto, esta pesquisa tem por objetivo a construção de um diagnóstico sobre a Educação Ambiental nas escolas públicas de educação básica no município de Parauapebas-PA. A opção teórico-metodológica utilizada foi a de pesquisa aplicada descritiva com a abordagem de caráter quanti-qualitativo. Para coleta de dados, foram utilizadas técnicas de análise documental, análise bibliográfica e levantamento através de questionários.

\section{Educação Ambiental}

Desde o início das primeiras sociedades humanas modernas, a exploração dos recursos naturais se tornou a maneira de acumulo de riquezas e poder. Ao passo que aquela se findava, e na busca de sobrevivência do grupo, iniciava-se expedições e lutas por territórios abundantes. Contudo, sempre se manteve tais recursos à mercê de sua ganância e exploração. Por outro lado, a arrogância humana em relação ao meio que vive, não lhe permitiu enxergar, por séculos, que todos esses recursos são limitados (PEDRINI, 1997, p.21). Diante desta percepção, e na tentativa de reversão desse quadro, se estabelece a necessidade de discussão sobre o modelo de desenvolvimento social ora utilizado, bem como seus impactos ao meio natural. Através de acordos internacionais, leis, programas e instrumentos, de ordem global e local, busca-se a sensibilização da sociedade sobre a importância da preservação do patrimônio natural (MENDES; LOPES; SALLES, 2014, p. 16) 
A conceituação de EA gera um debate no meio acadêmico, político e social, porém, uma definição pragmática sobre o tema consta nos anais da Conferência de Tbilisi (1977) que define a EA como:

...um processo de reconhecimento de valores e clarificação de conceitos, objetivando o desenvolvimento das habilidades e modificando atitudes em relação ao meio, para entender e apreciar as inter-relações entre humanos, suas culturas e seus meios biofísicos. A Educação Ambiental também está relacionada à pratica das tomadas de decisões e a ética que conduzem para a melhoria da qualidade de vida (CONFERENCIA INTERGOVERNAMENTAL DE TBILISI apud SATO, 2003, p.23)

Corroborando com este conceito, Carvalho (2004, p. 34) contextualiza que a EA surge das preocupações atuais da sociedade para com o destino e a qualidade de vida da presente e futuras gerações, inserindo-a como uma das alternativas para construção de novas concepções nas relações dos grupos sociais com o meio ambiente.

Neste contexto, podemos depreender que a Educação Ambiental busca a promoção de um processo educativo para a construção de um novo paradigma em relação sociedade-natureza, que contemple as aspirações populares de uma melhor qualidade de vida socioeconômica e almejando um mundo ecologicamente sadio.

\section{Educação Ambiental no Brasil}

A partir da Eco 92, a EA começa a se solidificar no Brasil como uma demanda institucional, abrindo caminho para a implantação de políticas públicas neste sentido. Guimarães (1995), aponta que, apesar do termo EA ter sido massificado à época, sua conceituação não estava clara para educadores e a população em geral, sendo confundido e aplicado como ensino de ecologia.

Outra problemática - que talvez tenha prejudicado a aplicabilidade correta da EA como política pública em seus primórdios - é o fato de que tenha sido tratada muito tempo como parte isolada apenas de questões ambientais, voltada para solução de problemas físicos do ambiente, e não na área de educação, sendo, desta forma, incapaz de discutir questões sociais e categorias teóricas da educação (LOUREIRO, 2004, p 81).

Em 1994 o então Ministério da Educação e do Meio Ambiente cria o Programa Nacional de Educação Ambiental (ProNEA), incluindo a EA no ensino formal, campanhas nacionais sobre EA, entre outras. No ano de 1996, através da Lei de Diretrizes e Bases da Educação Nacional (LDBEN n. 
9394/96) é previsto a inserção da EA aos conteúdos curriculares da educação básica.

Posteriormente, em 1997 são elaborados os Parâmetros Curriculares Nacionais (PCN's) que entre outros, define que o tema ambiental seja tratado transversalmente com eixos definidos nas disciplinas bem como esta temática não seja inserida como disciplina e sim como elemento a ser abordado nas variadas áreas do conhecimento. Em seguida, no ano de 1999, através da Lei 9.795 (BRASIL, 1999) é criada a Política Nacional de Educação Ambiental, definindo seus princípios e objetivos.

\section{Educação Ambiental nas escolas}

Apesar de ser sustentada em ordenamento jurídico através de leis, decretos, orientações e programas, a aplicação da EA, de fato, ainda gera muita discussão. Há dados do próprio Ministério da Educação (MEC) que apresentam as dificuldades ou compreensões dúbias da EA nas escolas brasileiras. Segundo o Programa Parâmetros em Ação Meio Ambiente na Escola, as escolas ainda se limitam a executarem a EA, quase que exclusivamente por projetos temáticos desarticulados do currículo, dificultando a interação entre as áreas do conhecimento.

Segundo Brasil (2001, p. 17-18) as práticas atuais de EA nas escolas se resumem em alguns itens: a) não está institucionalizada nas secretarias de educação, percebe-se a ausência de articulação com as demais políticas educacionais; b) o profissional que irá trabalhar a temática possui formação inicial deficitária, tradicional e fragmentada. Alimentando uma pratica de ensino descontextualizada da realidade em que irá atuar e não contempla a Educação Ambiental; c) os projetos não estão articulados ao projeto político pedagógico da escola; d) como área complexa que não se apresenta como disciplina específica, depende de discussão e acesso a informações atualizadas, visando à apropriação do repertório de conceitos específicos da temática.

Além disso, em 2004, o MEC - através da Coordenação Geral de Educação Ambiental (CGEA) em parceria com o Instituto de Estudos e Trabalhos e Sociedade (IETS), realizaram uma pesquisa a nível nacional intitulada "O que Fazem as Escolas que Dizem que Fazem Educação Ambiental?". Esta pesquisa abordou questionamentos como: incentivos, prioridades, atores envolvidos, modalidades, dificuldades e resultados em relação a EA em 418 escolas no Brasil. Seus resultados corroboraram com a percepção já arguida pelo próprio MEC anteriormente. Apesar disso, os resultados alcançados não podem ser generalizados para todas as regiões.

Neste sentido, a compreensão da importância e da necessidade dessa temática para sociedade, poderia implicar aos educadores um ímpeto de executar a EA sem antes considerar a práxis pedagógica, a contextualização regional e necessidade de recursos físicos e humanos. Portanto, é necessário que tenhamos um melhor aprofundamento sobre o tema, desde sua 
conceituação, metodologia, prática e aplicação social. E sob esse aspecto a presente pesquisa visa trazer à tona a forma que a EA tem sido abordada na educação básica neste município, podendo, à partir disso, abrir espaço para discussões, análises e novas perspectivas sobre a temática.

\section{Metodologia}

Com base na metodologia criada pela CGEA e o IETS, levando em conta sua relevância, alta qualidade e a imprescindível continuidade, a presente investigação a utilizara como base para o diagnóstico da Educação Ambiental no município de Parauapebas-PA. A opção teórico-metodológica utilizada foi a de pesquisa aplicada descritiva com a abordagem de caráter quanti-qualitativo. Para coleta de dados, foram utilizadas técnicas de análise documental, analise bibliográfica e levantamento através de questionários.

\section{Estrutura dos questionários}

Buscando a praticidade e eficiência bem como pensando na mitigação de impactos ambientais, os questionários foram elaborados de forma eletrônica - auto preenchíveis -, dispensando assim, a necessidade de impressão. Estes possuem 31 questões, sendo distribuídas entre questões dicotômicas, de múltipla escolha, de ordem de prioridades, e questões abertas. Vale frisar que, nas questões de múltipla escolha, o respondente poderia optar por mais de um item, fazendo com que a porcentagem (que são baseadas no número de escolas) possa ultrapassar os $100 \%$. O questionário foi articulado com as seguintes composições: a) Inserção da EA nas escolas de Parauapebas-PA (tempo, modalidade, características e temas estruturantes); b) Atores envolvidos nos Projetos de EA; c) Contribuições e Dificuldades para o desenvolvimento de EA; d) relação escola-comunidade; e) Relação entre professores, escola e Secretaria Municipal de Educação.

Os questionários foram encaminhados por correio eletrônico através da Diretoria Pedagógica da Secretaria Municipal de Educação (SEMED), para todas as escolas do município, acompanhados de orientações sobre a forma correta de preenchimento e da dispensabilidade de impressão.

\section{Locus}

O município de Parauapebas, está localizado no sudeste do estado do Pará. Segundo o Instituto Brasileiro de Geografia e Estatística (IBGE, 2010), o município de Parauapebas possui aproximadamente 196.259 habitantes. Segundo a SEMED, através do setor de estatística, o município possui 46.502 alunos regularmente matriculados, distribuídos em 67 escolas, sendo 35 de ensino fundamental e 20 de educação infantil. Vale ressaltar que, deste total, 55 escolas estão em área urbana, 9 em área rural e 3 em terras indígenas. (PARAUAPEBAS, 2019, p.2). 


\section{Resultados}

\section{Aplicação dos questionários}

Dos 67 questionários enviados, foram respondidos e entregues 51 questionários, configurando assim uma participação de aproximadamente $76 \%$ do público-alvo. Destes, 4 questionários foram invalidados por apresentarem erros no preenchimento ou estarem parcialmente respondidos. Configurando assim uma adesão real de aproximadamente $70 \%$ das escolas. Ressaltando que: a) grande parte das escolas que não responderam encontra-se em áreas rurais ou indígenas, indicando que uma metodologia específica de aplicação para esse público precisa ser desenvolvida; b) demonstra um percentual satisfatório para a amostragem desse diagnóstico.

\section{Inserção da EA nas escolas de Parauapebas-PA}

Em relação inserção da EA, foi apresentado que em apenas $58 \%$ das escolas desenvolvem atualmente, por outro lado, $42 \%$ das escolas nunca desenvolveram ou não desenvolvem mais a Educação Ambiental.

Em relação ao tempo que estas escolas desenvolvem EA, nota-se na Figura 1 abaixo, que em $60 \%$ das escolas desenvolve há menos de 3 anos, e em apenas $15 \%$ dos casos a presença da EA está há mais de 10 anos. O que nos leva e inferir que a EA pode ainda encontrar várias problemáticas quanto ao seu desenvolvimento e manutenção.

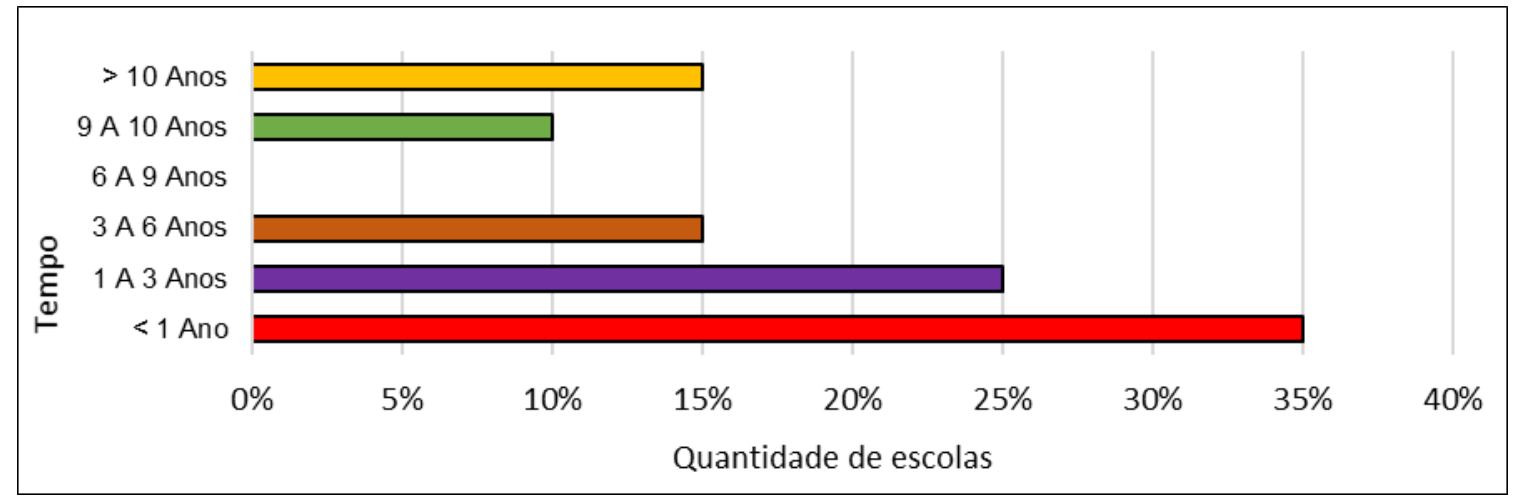

Figura 1: Distribuição das escolas segundo o tempo em que desenvolvem a EA Fonte: Autoria Própria

Quanto a motivação inicial para a inserção, é possível perceber na Figura 2, que está se dá por: iniciativa de um professor ou grupo de professores e através de políticas ou programas municipais de EA. Observa-se também que os problemas ambientais na comunidade são levados em consideração quanto a motivação para o desenvolvimento de EA na escola. 


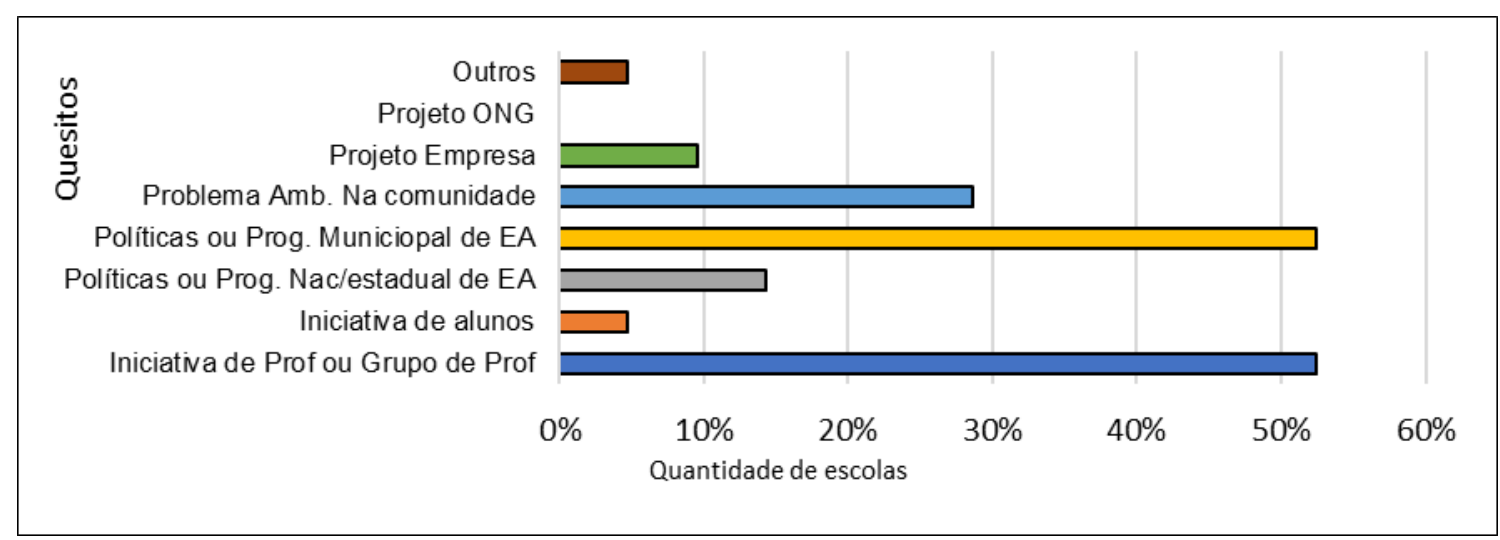

Figura 2: Motivação inicial para a inserção da EA na escola

Fonte: Autoria Própria

Ao tratarmos do objetivo da EA na escola, foi identificado a conscientização dos alunos e da comunidade para a plena cidadania como prioridade seguido do objetivo de intervir na comunidade, conforme apresentado na Figura 3. Depreende-se que a EA desenvolvida nestas escolas busca novas maneiras de propiciar o pensamento crítico reflexivo e o empoderamento cidadão frente as problemáticas socioambientais.

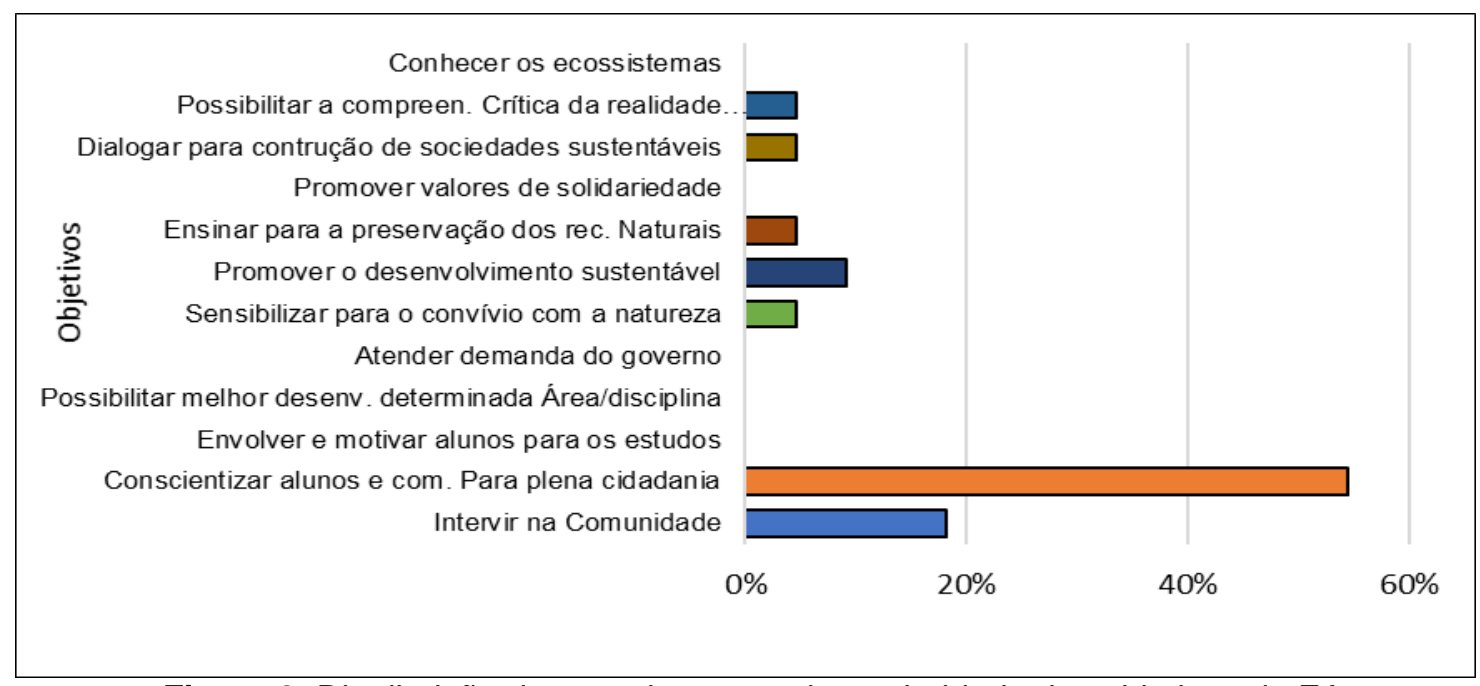

Figura 3: Distribuição das escolas segundo a prioridade dos objetivos da EA

Fonte: Autoria Própria

Em relação direta com o objetivo do desenvolvimento da EA na escola, foi constatado que a temática "água" é indicada por $58 \%$ dos respondentes como principal assunto para 0 a inserção e desenvolvimento da $E A$, seguido por "resíduos e reciclagem" com 16\%, de acordo com a Figura 4 . Reafirmando, desta maneira, o intento da EA sob um ponto de vista do enfrentamento dos problemas socioambientais. Salientamos ainda que, temas como Agenda 21, cultura e saberes tradicionais e populares, biomas e problemas rurais não foram citados pelos respondentes e por esse motivo não aparecem no gráfico.

Revbea, São Paulo, V. 15, № 7: 173-185, 2020. 


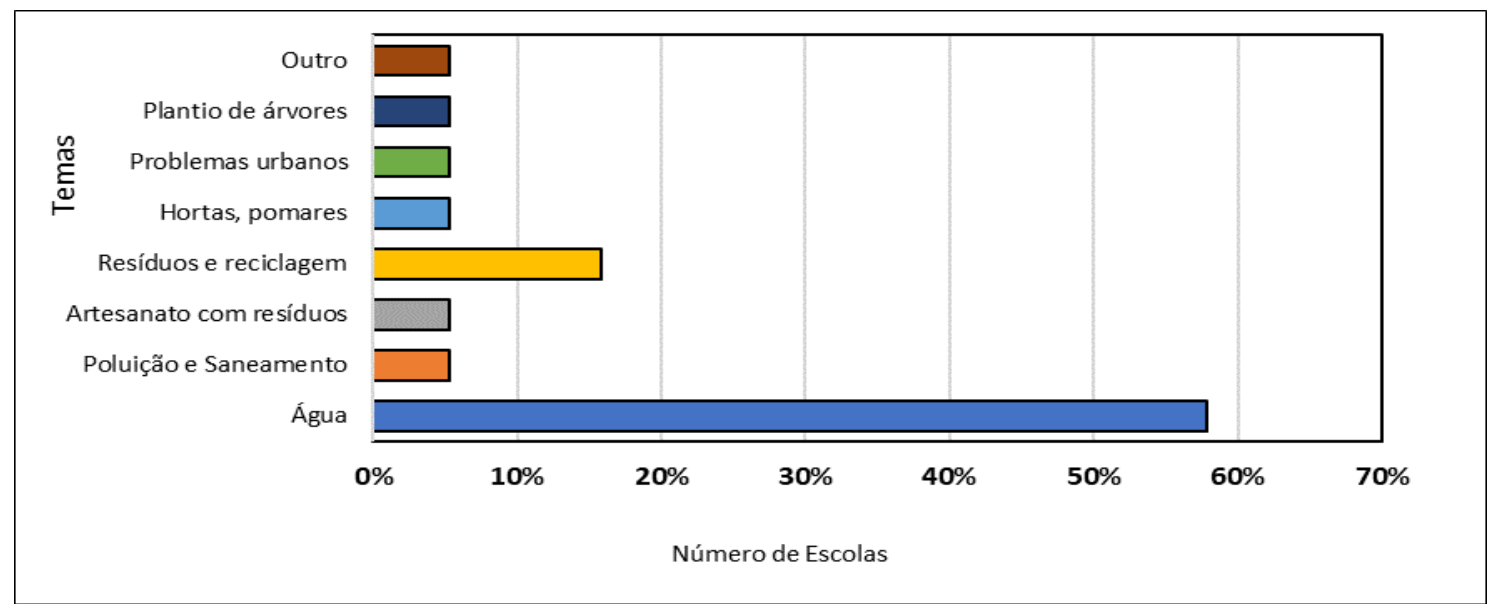

Figura 4: Distribuição das escolas segundo a principal temática da EA

Fonte: Autoria Própria

No que se refere a modalidade de inserção da EA na escola, nota-se na figura 5, que os Projetos, de forma absoluta, são utilizados em mais de $80 \%$ das escolas, seguido pela inserção no PPP com $27 \%$ e datas e eventos comemorativos com $23 \%$. Uma possível causa de as escolas trabalharem através de projetos, pode estar relacionada ao tempo e a motivação inicial da inserção, que é, respectivamente, menos de 3 anos e através dos professores. Apesar de, em alguns casos, os projetos apresentarem uma atuação pontual com fim pré-determinado, esta modalidade tende a ser mais flexível, quanto as temáticas e inclusiva, quanto a articulação intercurricular, o que possivelmente facilitaria a inserção da EA na escola em um primeiro momento.

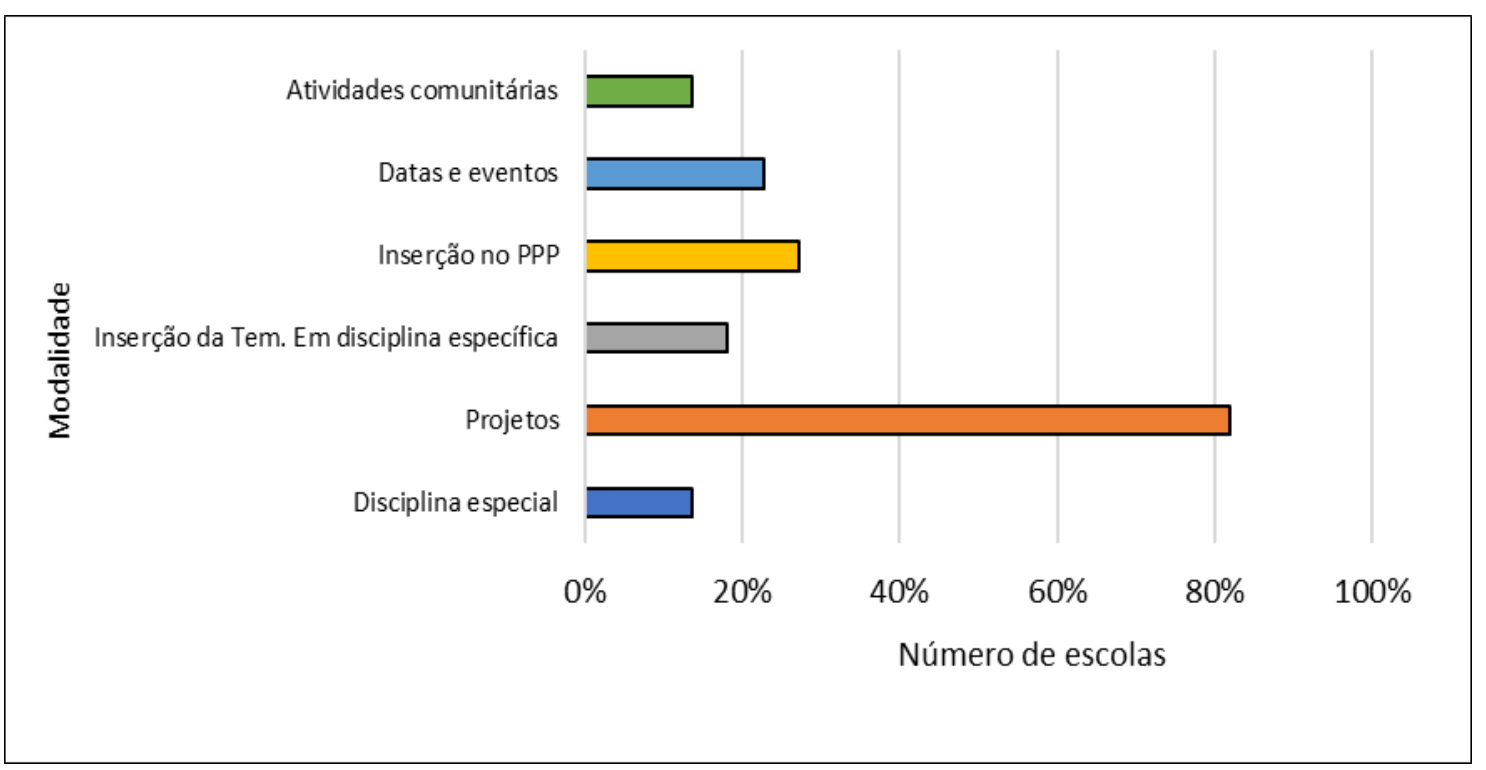

Figura 5: Modelo de aplicação da EA nas escolas

Fonte: Autoria Própria. 


\section{Atores envolvidos nos Projetos de EA}

Quanto à iniciativa para realização dos projetos, os resultados da pesquisa demonstram que em $94 \%$ das escolas esse início parte da equipe de direção e coordenação seguida por $88 \%$ dos casos em que a iniciativa parte de um grupo de professores. Por outro lado, nota-se uma pequena participação da sociedade nas escolas, sendo: $6 \%$ vindo de ONG's e apenas $19 \%$ partindo da comunidade. Esses dados revelam a percepção de uma tímida inclusão e interação entre escola e comunidade.

Nos projetos de EA, não necessariamente os mesmos atores envolvidos na iniciativa, são aqueles que se abarcam o desenvolvimento dos projetos. Os resultados da pesquisa apresentam que $100 \%$ da equipe de direção e coordenação estão envolvidas diretamente com os projetos, assim como $94 \%$ dos professores e dos alunos. Neste ponto, observa-se que, após iniciado o projeto a participação da comunidade sobe para $56 \%$. Infere-se então que, mesmo tendo um envolvimento, os projetos ainda acontecem de forma isolada dentro das escolas, sem a participação efetiva de todos os atores.

Em relação a gestão dos projetos é possível perceber que o planejamento, as tomadas de decisão e a avaliação são realizadas pelos professores, direção e coordenação, já na execução estão mais envolvidos professores, alunos e funcionários. Percebemos também que os atores externos à escola (comunidade, ONG, instituições, empresas) tem reduzida participação na gestão dos projetos.

Tabela 1: Atores que participam da gestão da EA na escola.

\begin{tabular}{lcccc}
\hline & Planejamento & Tomada de decisão & Execução & Avaliação \\
\hline Professores & $95 \%$ & $67 \%$ & $95 \%$ & $71 \%$ \\
Funcionários & $33 \%$ & $19 \%$ & $76 \%$ & $29 \%$ \\
Equipe de direção & $76 \%$ & $62 \%$ & $52 \%$ & $52 \%$ \\
Alunos & $19 \%$ & $14 \%$ & $86 \%$ & $24 \%$ \\
ONG & $10 \%$ & $10 \%$ & $5 \%$ & $10 \%$ \\
Comunidade & $19 \%$ & $14 \%$ & $48 \%$ & $24 \%$ \\
Instituição de Ensino & $19 \%$ & $14 \%$ & $29 \%$ & $14 \%$ \\
Empresa & $10 \%$ & $0 \%$ & $14 \%$ & $5 \%$ \\
\hline
\end{tabular}

Fonte: Autoria Própria. 


\section{Contribuições e dificuldades para o desenvolvimento de EA}

\section{Contribuições}

Em relação às contribuições referentes à inserção da $E A$, a formação continuada de professores é vista por $90 \%$ das escolas como um fator que contribui muito, assim como a presença de professores qualificados com formação superior e especializados foi apontado por $80 \%$ dos respondentes. Neste mesmo sentido em $70 \%$ dos casos o conhecimento das políticas e legislações públicas nacionais e internacionais sobre o meio ambiente e Educação Ambiental é visto como um fator que contribui muito.

No que se refere aos materiais pedagógicos inovadores e com maior fundamentação teórica os respondentes indicaram em $75 \%$ dos casos como um fator que contribui muito. Também foram apontados como fatores que contribuem muito para a inserção da EA: Bibliotecas bem equipadas - $40 \%$; Livros, jornais e revistas $-45 \%$ e Uso da internet $-60 \%$ das escolas.

Por outro lado, no item que se refere à participação da comunidade, $55 \%$ dos respondentes indicam que está contribui pouco para a inserção da EA nas escolas. Corroborando para o entendimento que as relações escolacomunidade ainda são frágeis e reduzidas, ou ainda que os objetivos gerais da EA não são bem compreendidos.

\section{Dificuldades}

As dificuldades apresentadas pelos respondentes para a efetiva inserção da EA, são: 1) precariedade dos recursos materiais; 2) falta de recursos humanos qualificados e 3) dificuldade da comunidade escolar (professores, coordenação, direção, funcionários, comunidade, etc) compreenderem a importância da Educação Ambiental. Essas dificuldades foram apresentadas pelas escolas que desenvolvem atualmente a EA nas escolas, bem como as que informaram que não desenvolvem ou nunca desenvolveram EA.

\section{Relação escola-comunidade}

Essa investigação identificou algumas relações e mudanças entre esses atores em relação a inserção da EA. Nota-se que nas ações realizadas dentro da escola e nas palestras realizadas pela escola, há uma relativa participação da comunidade, contudo a integração desta comunidade escolar com a sociedade civil da região (parceria em conselhos, conferências, comitês, etc) não é realizada em $45 \%$ dos casos. 
Tabela 2: Interação Comunidade Escola para o desenvolvimento da EA.

\begin{tabular}{lccc}
\hline & Sim & Às vezes & Não \\
\hline Parceria nas ações de EA dentro das escolas & $65 \%$ & $25 \%$ & $10 \%$ \\
Parceria nas ações de EA fora da escola & $35 \%$ & $30 \%$ & $30 \%$ \\
Palestras de sensibilização & $65 \%$ & $25 \%$ & $10 \%$ \\
Escola vai a comunidade realizar ações & $30 \%$ & $55 \%$ & $10 \%$ \\
Parceria em conferencias, conselhos, etc & $25 \%$ & $25 \%$ & $45 \%$ \\
\hline
\end{tabular}

Fonte: Autoria Própria.

Em relação às mudanças percebidas na escola após a inserção da EA, observa-se que: a) alunos ficaram mais sensíveis à conservação do patrimônio público; b) houve uma significativa redução do lixo nas escolas; c) houve melhorias nos relacionamentos entre alunos, professores e funcionários da escola; d) a incorporação de novas práticas pedagógicas.

Já as mudanças percebidas na comunidade após a inserção da EA, houve as seguintes melhorias: a) maior sensibilização dos moradores para conservação do patrimônio público; b) melhorias no entorno da escola; c) maior articulação entre projetos da escola e as necessidades da comunidade.

\section{Relação entre professores, escola e Secretaria Municipal de Educação}

A presente pesquisa também procurou entender quais seriam as ações promovidas pela SEMED/Parauapebas que poderiam contribuir para a inserção e desenvolvimento da EA nas escolas. Foi questionado se esta Secretária fornecia algum tipo de formação específica para a EA ou se dentro das formações regulares era abordada essa temática: $71 \%$ responderam que sim. Sobre outras ações dessa Secretaria que eventualmente poderiam contribuir para uma efetiva inserção da EA nas escolas, obtivemos os seguintes resultados: $79 \%$ dos respondentes acreditam que o incentivo à qualificação dos professores apresentaria resultados significativos; $58 \%$ informaram que incentivos à participação em congressos, seminários, oficinas, etc., através de horas-atividade estimulariam os professores à se qualificarem; e 54\% acreditam que a ajuda de custos específicas para os professores que fomentem ou desenvolvam a EA, seria uma contribuição expressiva.

Em relação as ações que a Secretaria poderia promover diretamente para as escolas, no que tange as contribuições para inserção da EA, os resultados obtidos, em ordem de importância, são: 1) qualificação do professores e equipe de direção; 2) aquisição e distribuição de material pedagógico sobre EA; 3 ) convênios com outras instituições de ensino para o intercâmbio de professores e equipe de direção, com objetivo de troca de experiências em relação a EA. 


\section{Conclusões}

A EA no município de Parauapebas-PA ainda é recente e este fato pode ter relevância na metodologia que é aplicada para o desenvolvimento da EA e ainda na sua continuidade e amplitude. Observa-se que a avaliação sobre a contribuição da comunidade no desenvolvimento dos projetos de EA foi considerada pouco relevante, resumindo este grupo apenas como receptor ou espectador e centrando a atuação no interior das escolas. O que podemos concluir como uma deficiência nos conhecimentos práticos e metodológicos sobre a temática.

Conclui-se que, por mais que a comunidade escolar apresente nobres e relevantes objetivos e iniciativas para inserir a EA nas escolas de Parauapebas, será necessário intervenções de políticas públicas especificas para seu pleno desenvolvimento. Nas escolas que desenvolvem a EA ainda existem entraves práticos ou metodológicos a serem superados - materiais e recursos humanos qualificados. A compreensão da importância, dos objetivos e finalidades da Educação Ambiental por parte da comunidade escolar neste município, atrelados a maiores investimentos na capacitação dos educadores, talvez seja o primeiro passo a ser superado para o pleno desenvolvimento da Educação Ambiental.

Espera-se que este diagnóstico possa embasar uma análise mais aprofundada da Educação Ambiental em Parauapebas, assim como servir de subsídios para o fomento de políticas públicas e criação de novas ferramentas para melhoria de sua qualidade.

\section{Referências}

BRASIL. Lei 9795, de 27 de abril de 1999. Dispõe sobre a Educação Ambiental, institui a Política Nacional de Educação Ambiental e dá outras providencias. Brasília, 27 abr. 1999.

BRASIL, Ministério da Educação e Desporto. Secretaria de Educação Fundamental. Parâmetros Curriculares Nacionais: Documento Introdutório. Brasília: MEC, 1997. 54p.

BRASIL. Presidência da República. Lei 9394, de 24 de dezembro de 1996. Estabelece as diretrizes e bases da educação nacional. Brasília, 20 dez. 1996.

BRASIL. Presidência da República. Programa Parâmetros em Ação Meio Ambiente na Escola. Brasília: MEC, 2001.

CARVALHO, I.C. de M. Educação Ambiental: a formação do sujeito ecológico. 2 ed. São Paulo: Cortez, 2004.

GUIMARÃES, M. A dimensão ambiental na educação. Campinas: Papirus, 1995.

INSTITUTO BRASILEIRO DE GEOGRAFIA E ESTATÍSTICA (IBGE). Censo Demográfico 2010. Rio de Janeiro, 2010. 
LOUREIRO, C.F.B. Trajetória e fundamentos da Ed. Ambiental. São Paulo: Cortez, 2004.

MENDES, F.C.P., LOPES, C.V.G., SALLES, J.O. Educação e meio ambiente. Curitiba: Fael, 2014.

PARAUAPEBAS (Cidade). Secretaria Municipal de Educação. Departamento de Estatística. Número de alunos matriculados. Parauapebas, 2019.

PEDRINI, A. de G. (Org.). Educação Ambiental: reflexões e práticas contemporâneas. Petrópolis: Vozes, 1997.

SATO, M. Educação Ambiental. São Carlos: Rima, 2003. 